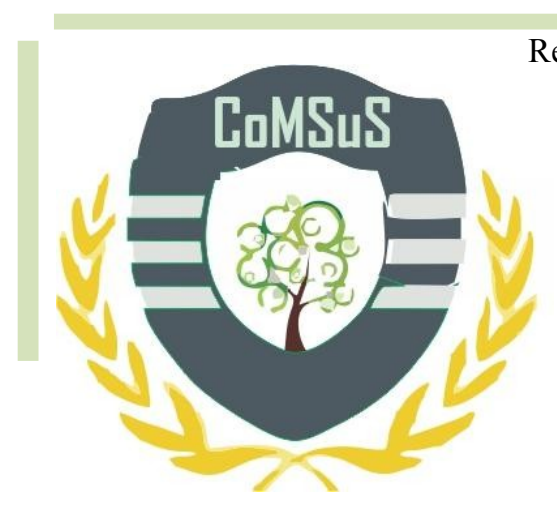

Recebido em 08/02/2017. Revisado em 23/05/2017. Aprovado em 06/06/2017. Editor: Dr. Ivano Ribeiro

Processo de Avaliação: Double Blind Review e-ISSN: $2359-5876$

https://doi.org/10.5935/2359-5876.20170002

\title{
CITY MANAGER: UMA PROPOSIÇÃO DE UM PROJETO DE LEI NOS MUNICÍPIOS BRASILEIROS
}

\author{
João Augusto Wendt Mischiatti ${ }^{1}$ \\ Anderson Catapan ${ }^{2}$
}

\begin{abstract}
RESUMO
Este estudo tem como objetivo propor a implementação do City Manager nas prefeituras do Brasil, visando à profissionalização da gestão municipal e consequentemente à redução nos índices de corrupção. Para isto, como metodologia de pesquisa, foram analisados artigos e legislações internacionais relativas ao City Manager. Dentre esses, foram selecionados um universo de 35 artigos, sem limite da data de publicação, os quais atendiam aos critérios usados para a seleção. Da mesma forma, realizou-se buscas em manuais, legislações e organogramas referentes ao cargo pesquisado. As legislações encontradas e o ICMA delineiam o City Manager como principal administrador da cidade. Dos 35 artigos, 16 mencionam que este administrador municipal trouxe benefícios no combate a corrupção e/ou aumento da eficiência na gestão, em contraponto nenhum dos artigos selecionados menciona outra forma de governo, sem a utilização do City Manager, capaz de trazer resultados melhores ou equivalentes nesses quesitos. Evidenciou-se que esta forma de gestão municipal apresentou resultados de sucesso em várias prefeituras nos Estados Unidos e em outros países, com isto surge esse estudo trazendo como proposta um projeto de lei federal com as diretrizes gerais de implementação, dos poderes e dos deveres do City Manager nas prefeituras brasileiras contribuindo com a melhoria da gestão nas organizações municipais.
\end{abstract}

Palavras-chave: Municípios. City Manager. Gestão Pública. Corrupção.

\section{CITY MANAGER: A PROPOSAL FOR A LAW PROJECT IN BRAZILIAN MUNICIPALITIES}

\begin{abstract}
This study aims to propose a implementation of the City Manager in Brazilian cities, targeting at the professionalization of municipal management and consequently the reduction in corruption rates. For this, as a research methodology, articles and international legislations, related to the City Manager, were analyzed. Among these, a universe of 35 articles were selected, with no publication date limit, which met the criteria selected. In the same way, searches were made on manuals, legislations and

${ }^{1}$ Especialista em Planejamento e Gestão Estratégica e Administração e Finanças pela UNINTER. Analista de Gestão pela Fundação Oswaldo Cruz, FIOCRUZ. E-mail: joaomischiatti@,hotmail.com.

${ }^{2}$ Pós-Doutor em Gestão pela Universidade Fernando Pessoa (Portugal). Doutor em Administração pela Pontifícia Universidade Católica do Paraná (PUCPR) com período de estágio sanduíche na Universidade do Porto (Portugal). Professor Adjunto da Universidade Tecnológica Federal do Paraná, UTFPR. E-mail: catapan@utfpr.edu.br.
\end{abstract}


organizational charts related to this position. The legislations found and the ICMA outline the City Manager as the city's main administrator. Of the 35 articles, 16 mentions that this manager brought benefits in the fight against corruption and / or increased efficiency in management, in counterpoint none of the selected articles mentions another form of government, without the use of City Manager, able to bring results better or equivalent in these matters. It was evidenced that this management form presented successful results in several prefectures in the United States and in other countries, with this comes the study bringing as a proposal of a federal law with the general guidelines of implementation, powers and duties of the City Manager in Brazilian municipalities contributing to the improvement of management in municipal organizations.

Keywords: Cities. City Manager. Public administration. Corruption.

\section{CITY MANAGER: UNA PROPOSICIÓN DE UN PROYECTO DE LEY EN LOS MUNICIPIOS BRASILEÑOS}

\section{RESUMEN}

El objetivo de este estudio es proponer la implementación del City Manager en las ciudades brasileñas, enfocándose en la profesionalización de la gestión municipal y consecuentemente en la reducción de las tasas de corrupción. Para ello, como metodología de investigación, se analizaron artículos y legislaciones internacionales, relacionadas con el City Manager. Entre ellos, se seleccionó un universo de 35 artículos, sin límite de fecha de publicación, que cumplía con los criterios seleccionados. De la misma manera, se realizaron búsquedas en manuales, legislaciones y organigramas relacionados con la posición de City Manager. Las legislaciones encontradas y el ICMA describen al City Manager como el administrador principal de la ciudad. De los 35 artículos, 16 mencionan que el Administrador de la ciudad trajo beneficios en la lucha contra la corrupción y / o mayor eficiencia en la gestión, en contrapunto ninguno de los artículos seleccionados menciona otra forma de gobierno, sin la Mejores resultados o equivalentes en estas materias. Se evidenció que el cargo presentó resultados exitosos en varias prefecturas en los Estados Unidos y en otros países, con esto viene el estudio aportando como propuesta de una ley federal con las directrices generales de implementación, atribuciones y deberes del City Manager en Municipios brasileños Contribuyendo con la mejora de la gestión en las organizaciones municipales.

Palabras clave: Ciudades. City Manager. Administración Pública. Corrupción. 


\section{INTRODUÇÃO}

A administração pública possui grandes desafios a serem enfrentados em todas as esferas de governo. Esses desafios englobam a gestão de sua estrutura, a busca de informações relevantes e confiáveis que possam ser utilizadas da melhor forma para o cidadão, e processos que sejam organizados de uma forma econômica e eficiente, além de um controle adequado de toda a gestão pública (Pfeiffer, 2000; Rezende, 2005).

Com o surgimento desses desafios nasceu, na administração pública, um modelo condizente com as técnicas de produção e de gestão da administração privada. Na gestão pública municipal, tal efeito também se propagou, os municípios buscaram utilizar novas tecnologias, novos modelos e meios de modernizar sua gestão como um todo, para que assim conseguissem entregar um melhor serviço aos cidadãos de acordo com os recursos disponíveis, porém não tão bem conduzido como a administração pública federal (Leite \& Rezende, 2010).

Estudiosos e políticos buscam constantemente obter ferramentas que melhorem o desempenho governamental. Segundo Demir (2011), nos Estados Unidos e em diversos outros países o papel do city manager é muito significativo e foi fundamental para a melhoria na gestão pública. O city manager é um funcionário, em regra, com grande experiência em administração pública, e nomeado pela câmara de vereadores de acordo com o seu currículo. Este administrador terá poderes administrativos para gerenciar a prefeitura, por exemplo, nas cidades americanas ele é responsável pela contratação dos funcionários administrativos, supervisão de obras, execução do orçamento conforme planejado, gerar relatórios financeiros e contábeis, entre outras funções (Couperus, 2014).

Os City Managers em diversos países desenvolvidos detinham conhecimento técnico de gestão, pois são escolhidos pelo seu currículo e não pelo voto direto, sendo desse modo responsáveis pelo fornecimento de técnicas para um processo de gestão de qualidade e de assessores neutros para os funcionários eleitos (Demir, 2011).

Apesar da implementação dos City Managers ter sido um sucesso nos municípios norteamericanos, na América Latina não houve a implementação dessa função (Ammons, 2008; Mischiatti et al., (2016). Os municípios brasileiros não apresentam um quadro diferente do exibido na América Latina, pois a liderança do prefeito predomina em todos os aspectos, tanto administrativo como político, sendo o prefeito responsável pelas funções de gestão política e de gestão administrativa dos municípios (Ammons, 2008).

Este artigo propõe um novo modelo para a gestão pública municipal baseada na forma de governo conselho-gerente. Este modelo traz as diretrizes para implementação do cargo de City Manager nos munícipios brasileiros com o objetivo de proporcionar uma gestão com maior eficiência, profissionalismo e que consequentemente ajude a inibir os índices de corrupção.

Essa implantação desses gestores municipais faria com que houvesse uma segregação das funções, a qual afastaria a influência política e o controle do prefeito, neste caso, os índices de corrupção seriam reduzidos (Noordegraaf, 2007; Reddick \& Demir, 2014).

Um maior profissionalismo e eficiência também são destacados como objetivos da implantação do City Manager no processo de administração municipal (Ammons, 2008). Frente a relevância do tema, a questão de pesquisa do presente artigo é: existe a possibilidade de implementar o City manager nas prefeituras dos munícipios brasileiros?

Segundo Mischiatti et al. (2016), não há nenhum estudo de artigos publicados em periódicos envolvendo a figura do City Manager na América Latina. Existe portanto uma lacuna de trabalhos que enfoquem a possível implementação do City Manager nos munícipios brasileiros. Neste cenário, propõe-se uma forma de governo, ainda não implementada em 
nenhum país da América Latina, a qual pode contribuir para um governo mais transparente e profissional nas prefeituras brasileira.

\section{REFERENCIAL TEÓRICO}

Em praticamente todo os EUA, durante o início do século xx até a década de 50, os procedimentos de governança urbana tinham sido dominados por notáveis ricos, os quais exerciam uma política imposta à comunidade local, através dos chefes locais do partido, de uma administração municipal controlada (dividindo escritórios entre parentes e amigos) em que se conduziam os resultados das eleições (através da compra de votos, particularmente, entre grupos de imigrantes). A partir do final do século XIX a expressão "bom governo" ganhou força em diversas cidades americanas, e para resolver os problemas do governo da cidade começou-se a se refletir sobre uma reforma municipal durante a Era Progressista (Couperus, 2014).

O sistema que apresentava o prefeito como centro de todo o poder criou um vazio de liderança que foi rapidamente preenchido por máquinas partidárias, cujos chefes políticos controlavam e manipulavam a votação. Após a eleição, os chefes políticos comandavam as autoridades eleitas, determinando como essas deviam executar as operações locais. Geralmente de uma forma que eles e seus aliados enriquecessem ainda mais. A administração dos municípios era organizada e conduzida com base em favores pessoais, acordos políticos e lucro privado. Essa máquina política do partido resultou em muita ineficiência e gastos excessivos de dinheiro público local (Couperus, 2014).

Para remediar esta situação, reformadores procuraram aplicar os princípios da administração científica na gestão municipal (Ammons, 2008). Entre esses, o plano de conselho-gerente para as cidades, originado por Richard Childs em 1908. Esse plano procurou trazer um equilíbrio de responsabilidade política democrática e uma administração competente para o governo local (Hirschhorn, 1997).

O plano de Childs era empregar uma pessoa politicamente neutra, um gerente especialista para servir ao município. Esse por sua vez, seria escolhido pelo conselho municipal e, deveria executar fielmente as decisões do órgão eleito, devendo principalmente resguardar o bem-estar dos cidadãos, utilizando-se, para isso, das boas práticas empresariais a fim de administrar de forma eficiente a cidade (Hirschhorn, 1997).

Pensando nessa reforma política para um bom governo, surge a figura do City Manager para uma gestão profissional das cidades. Muitos estudiosos referem-se ao primeiro City Manager em 1908 na cidade de Staunton, Virginia, através da decisão do Conselho da Cidade (Avallaneda, 2009). Desse modo, os EUA formaram um terreno fértil da gestão municipal. Durante as décadas de 1910 e 1920, muitas cidades americanas adotaram este novo sistema de governo em que um perito nomeado, City Manager, cada vez mais se tornará um funcionário fundamental na prestação dos serviços municipais (Adrian 1999; Couperus, 2014).

Nesta época os EUA tornaram-se um laboratório para o mundo no que se refere a administração municipal. Diversas cidades que enfrentavam sérias dificuldades fizeram a referida reforma e foram bem-sucedidas tais como: Nova York, Pittsburgh, Baltimore, Chicago, Cleveland, Detroit, entre outras cidades (Couperus, 2014). Segundo Rightor, (1919) a cidade deveria ser considera uma grande empresa de negócios cujos acionistas são as pessoas. Os assuntos municipais devem ser geridos por pessoas qualificadas em gestão de negócios ou ciências sociais. $\mathrm{O}$ dinheiro do povo gasto com sabedoria e economia, sem desperdício, para o benefício de todos os cidadãos.

Segundo White (1927), não havia dúvida de que os City Managers foram um grande 
sucesso para as cidades. Claramente, esses gestores foram mais atentos em relação a poupança, planejaram com mais precisão e lideraram as aquisições com eficiência. Implementaram diversas melhorias na gestão municipal e nesta época, constantemente, buscaram resolver os problemas de forma técnica e objetiva.

Na maioria dos munícipios americanos, os City Managers são escolhidos pelo Conselho municipal eleito pelo povo, tal Conselho possui atividades semelhantes a câmara municipal, visto que seus integrantes são incumbidos da função de supervisionar o poder executivo, aprovar o orçamento da cidade e representar a municipalidade em diversas tarefas. Os City Managers supervisionam todas as tarefas administrativas necessárias, procuram resolver problemas administrativos e também aconselham o prefeito e os membros do conselho no intuito de garantir que esses realizem melhores investimentos e escolhas para a população (Morgan \& Watson, 1992).

As atividades desempenhadas pelo City Manager variam de acordo com o porte e as características da cidade. Na maioria das grandes cidades esses gerentes possuem o auxílio de diversos membros os quais os ajudam nas tarefas de gestão, enquanto em cidades menores a variedade de afazeres aumenta. Contudo, independentemente do tamanho dos munícipios os City Managers são responsáveis pela execução do orçamento municipal a ser realizada de acordo com as diretrizes municipais, sendo responsável também pela fiscalização dos departamentos, entre outros assuntos internos e externos (Nalbandian, 1999).

A posição do City Manager vem aumentando nos EUA, segundo Mikheeva e Kudryavtsev (2015), no ano de 2014, 90\% dos municípios dos EUA possuíam o cargo de gerentes em suas prefeituras. Isso também é verificado no estado de Carolina do Norte, onde em 2012, suas 34 maiores cidades haviam designado um City Manager para gerir administrativamente o município. Quanto as cidades com mais de 2.500 (dois mil e quinhentos) habitantes, $85 \%$ dessas possuíam o referido cargo em seus municípios (Stenberg, 2014).

\section{METODOLOGIA}

Este estudo se baseou na revisão da literatura através de uma busca de periódicos, normas, legislação, regras e manuais de diferentes países. Entre os meses de junho a agosto de 2016, foram realizadas buscas de artigos em diversas bases de dados utilizando-se a palavrachave "City Manager".

Para a seleção dos artigos utilizou-se as bases de dados SciELO, Scopus e Web of Science. A base de dados Web of Science é a base de dados de maior relevância internacionalmente e possui mais de doze mil revistas cadastradas, as quais possuem ISI (International Scientific Information) (FAHIMNIA et al. 2015, MISCHIATTI et al., 2016).

A base de dados SciELO possui grande relevância na literatura científica nacional (Mischiatti, et al. 2016). Já a base de dados Scopus foi escolhida por ser o maior banco de dados de periódicos do mundo, sua cobertura inclui dezena de milhões de artigos revisados por pares (Chicksand et al., 2012; Fahimnia et al., 2015; Mischiatti et al., 2016).

$O$ filtro realizado para a pesquisa em cada uma das bases de dados foi a palavra "city manager". Apenas periódicos publicados em língua inglesa ou portuguesa, e sem limite de data de publicação, foram consideras. Foram retirados artigos repetidos e artigos que não apresentassem relação com a pesquisa. Somente foram classificados para esta pesquisa artigos categorizados nos seguintes tópicos: características da Profissão do City Manager, City Manager e as questões políticas, e questões éticas e valores presentes na profissão do City Manager. 
Entre os meses de outubro e novembro foram realizadas buscas através da internet a respeito da legislação, manuais e normas referentes ao cargo de "City Manager". Encontrou-se o Estatuto Geral da Carolina do Norte, o Estatuto de Wisconsin, Estatuto Revisado de Missouri os quais disciplinam os poderes, deveres e diretos do City Manager, recomendações da International City/County Management Association (ICMA) e o organograma da cidade de Austin, Texas.

A próxima fase foi realizar o levantamento de informações para elaborar a pesquisa exploratória. O objetivo deste levantamento foi entender como solucionar o problema de pesquisa e buscar mais informações de como outros países e munícipios resolveram problemas similares (Cooper \& Schindler, 2003).

Tabelas e quadros foram realizados para mostrar uma melhor ilustração das informações obtidas neste estudo. Com todos esses dados disponíveis foi proposto um projeto de lei referente as diretrizes de implementação, poderes e deveres do City Manager nos munícipios brasileiros.

\section{RESULTADOS E DISCUSSÕES}

Esta busca inicial de periódicos resultou em um universo de 133 artigos. Após a exclusão de artigos repetidos e considerando os critérios de categorização estabelecidos anteriormente chegou-se a um número de 35 artigos. Conforme a Tabela 01 apresenta, verificou-se que 15 artigos abordam as "Diferenças e similaridades dos City Managers e dos oficiais eleitos"; 11 desses trazem informações sobre "City Manager e as questões políticas" e 09 artigos explicitam as "Questões éticas e valores na profissão do City Manager".

Tabela 1. Assuntos presentes nos artigos analisados

\begin{tabular}{lc}
\hline \multicolumn{1}{c}{ Assunto } & $\mathbf{N}^{\mathbf{0}}$ de artigos \\
\hline Diferença e similaridades dos City Managers e dos oficiais eleitos & 15 \\
\hline City Manager e as questões políticas & 11 \\
\hline Questões éticas e valores na profissão do City Manager & 09 \\
\hline Total & 35 \\
\hline
\end{tabular}

Fonte: Dados da pesquisa (2016)

O Quadro 1 mostra as principais atribuições poderes e deveres do City Manager quando utilizada a forma de conselho-gerente. Trazendo como parâmetro a legislação da Carolina do Norte especificado no G.S 153 A-82, o Estatuto de Wisconsin, o Estatuto Revisado de Missouri e o Internacional City/County Management Association (ICMA).

Quadro 1. Atribuições, poderes e deveres do City Manager

\begin{tabular}{|c|c|c|c|c|}
\hline$\frac{\text { Atribuições, poderes e deveres }}{\text { do City Manager }}$ & $\frac{\frac{\text { Legislação da }}{\text { Carolina do }}}{\underline{\text { Norte }}}$ & $\begin{array}{l}\text { Estatuto de } \\
\text { Wisconsin }\end{array}$ & $\begin{array}{c}\text { Estatuto } \\
\text { Revisado de } \\
\text { Missouri }\end{array}$ & $\begin{array}{c}\text { International } \\
\text { City/County } \\
\text { Management } \\
\text { Association } \\
\text { (ICMA) }\end{array}$ \\
\hline $\begin{array}{l}\text { O City Manager deve ser o } \\
\text { principal administrador da cidade e } \\
\text { será responsável, perante o } \\
\text { conselho, da administração de } \\
\text { todos os assuntos municipais } \\
\text { colocados sobre } \\
\text { responsabilidade. }\end{array}$ & Apresenta & Apresenta & Apresenta & $\underline{\text { Apresenta }}$ \\
\hline
\end{tabular}




\begin{tabular}{|c|c|c|c|c|}
\hline$\frac{\text { Atribuições, poderes e deveres }}{\underline{\text { do City Manager }}}$ & $\frac{\frac{\text { Legislação da }}{\text { Carolina do }}}{\underline{\text { Norte }}}$ & $\begin{array}{l}\text { Estatuto de } \\
\text { Wisconsin }\end{array}$ & $\begin{array}{l}\text { Estatuto } \\
\text { Revisado de } \\
\text { Missouri }\end{array}$ & $\begin{array}{c}\text { International } \\
\text { City/County } \\
\text { Management } \\
\text { Association } \\
(\text { ICMA) }\end{array}$ \\
\hline $\begin{array}{l}\text { Nomear e suspender ou retirar } \\
\text { todos os oficiais da cidade e os } \\
\text { funcionários não eleitos pelo povo, } \\
\text { e cuja nomeação ou remoção não } \\
\text { for de outra forma prevista em lei, } \\
\text { exceto o advogado da cidade, de } \\
\text { acordo com as regras gerais de } \\
\text { pessoal, regulamentos, políticas ou } \\
\text { ordenanças como o Conselho pode } \\
\text { adotar. Porém ele é obrigado a } \\
\text { nomear os funcionários sempre por } \\
\text { mérito. }\end{array}$ & Apresenta & Apresenta & Apresenta & Apresenta \\
\hline $\begin{array}{l}\text { Terá o poder de criar escritórios } \\
\text { administrativos menores, posições } \\
\text { e descontinuar essas cargos e } \\
\text { posições de acordo com o seu } \\
\text { julgamento sempre se baseando } \\
\text { nas necessidades da cidade. }\end{array}$ & Apresenta & Apresenta & $\underline{\text { Não apresenta }}$ & $\underline{\text { Não apresenta }}$ \\
\hline $\begin{array}{l}\text { Dirigir e supervisionar } \\
\text { administração de todos os } \\
\text { departamentos, escritórios e } \\
\text { agências da cidade, sujeito à } \\
\text { direção e ao controle do conselho } \\
\text { geral, salvo disposição em } \\
\text { contrário por lei. Dessa forma os } \\
\text { membros do conselho devem lidar } \\
\text { com os empregados através do } \\
\text { gestor municipal. Princípio da não } \\
\text { interferência. }\end{array}$ & Apresenta & Apresenta & Não apresenta & Não apresenta \\
\hline $\begin{array}{l}\text { Ser responsável por verificar que } \\
\text { todas as legislações são fielmente } \\
\text { executadas dentro da cidade. }\end{array}$ & Apresenta & Apresenta & Apresenta & Apresenta \\
\hline $\begin{array}{l}\text { Assistir às reuniões do conselho e } \\
\text { recomendar quaisquer medidas que } \\
\text { ele considere oportuno }\end{array}$ & Apresenta & Apresenta & Apresenta & Apresenta \\
\hline $\begin{array}{l}\text { Possuir direito a voto nas decisões } \\
\text { do conselho }\end{array}$ & Não apresenta & Apresenta & Não apresenta & Não apresenta \\
\hline $\begin{array}{l}\text { Prestar relatórios e contas } \\
\text { mensalmente para o conselho. }\end{array}$ & Apresenta & Apresenta & Não apresenta & Não apresenta \\
\hline $\begin{array}{l}\text { Apresentar anualmente ao } \\
\text { Conselho e colocar à disposição do } \\
\text { público um relatório completo } \\
\text { sobre as finanças e atividades } \\
\text { administrativas da cidade a partir } \\
\text { do final do ano fiscal. }\end{array}$ & Apresenta & Apresenta & Apresenta & Apresenta \\
\hline $\begin{array}{l}\text { Preparar e apresentar o orçamento } \\
\text { anual para o conselho }\end{array}$ & Apresenta & Apresenta & Apresenta & Apresenta \\
\hline
\end{tabular}

Fonte: Dados da pesquisa (2016) 
Os dados do Quadro 1 demonstram que se apresenta como unânime nas legislações sobre o City Manager o poder desse no que concerne a nomeação de todos os seus subordinados. Ressalva-se que as nomeações devem ser puramente de mérito, com vista a assegurar o melhor nomeado disponível para o lugar. A devida consideração deve ser dada à formação, experiência, capacidade, as qualificações gerais e a aptidão para o desempenho das tarefas de escritório, não devendo ser considerados e apresentar nenhum peso características como a residência, a nacionalidade ou filiação política ou religiosa.

Há um consenso em grande parte das atribuições e poderes do City Manager tais como: apresentar relatórios financeiros anualmente, preparar e apresentar o orçamento anual para o conselho, executar fielmente a legislação da cidade. Porém, uma das principais divergências explicitadas no Quadro 1 refere-se o City Manager possui direito ao voto nas decisões do conselho municipal, sendo o Estatuto de Wisconsin o único a conferir esse poder de voto ao City Manager.

Os governos locais nos EUA têm a possibilidade de operar sob diferentes formas de governo: a forma de conselho-gerente; um prefeito-conselho; ou uma forma alternativa que esteja em conformidade com a lei estadual (Couperus, 2014).

A Figura 1 a seguir apresenta o organograma da cidade de Austin, Texas Estados Unidos. Nesta cidade, os prefeitos juntamente com a sua comissão elegem o City Manager figurando como forma de governo o Conselho-gerente.

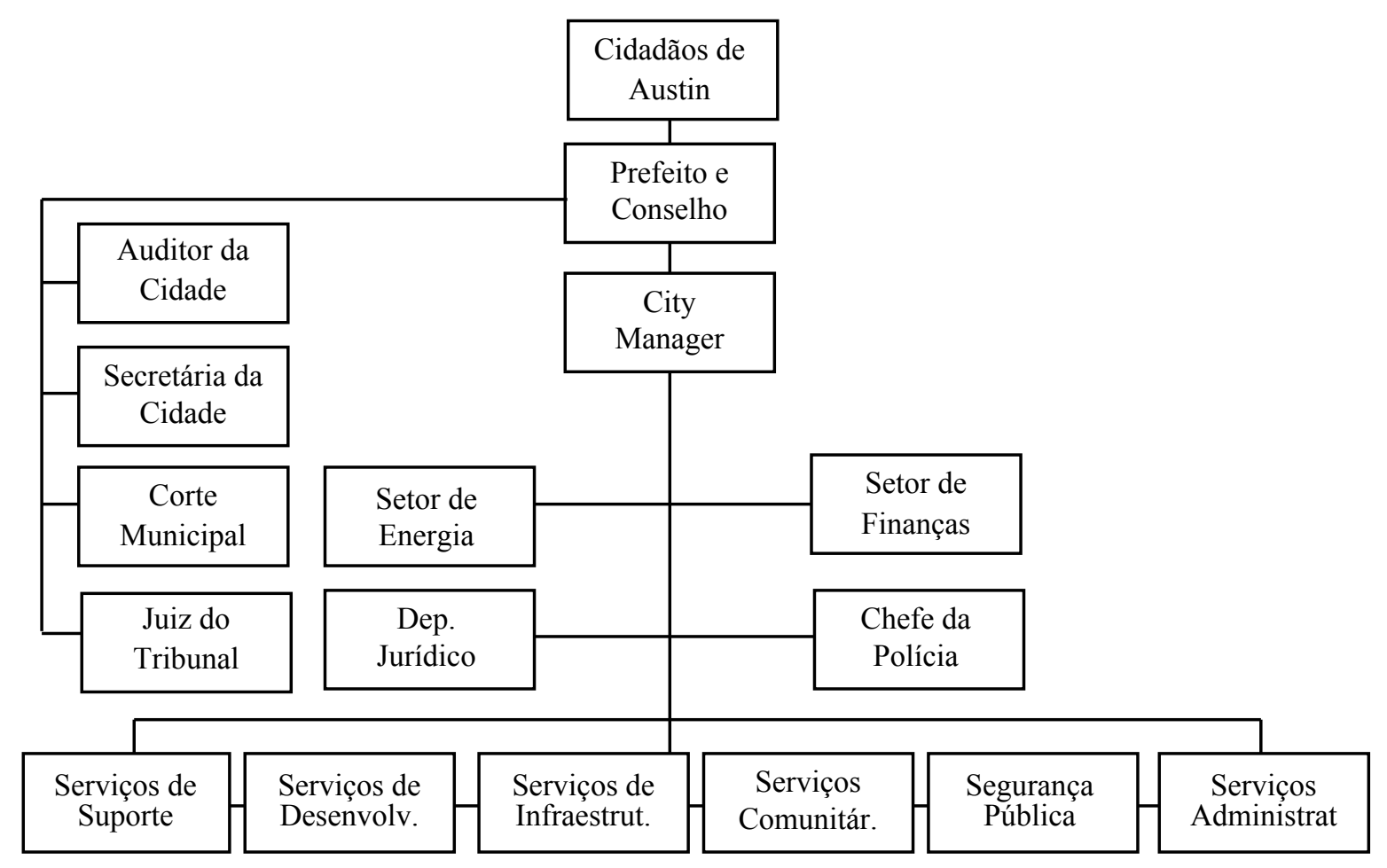

Figura 1. Organograma da Cidade de Austin, Texas, EUA

Fonte: Organograma da cidade de Austin, Texas Estados Unidos, retirado do site: http://www.austintexas.gov/sites/default/files/files/City_Org_Chart_10_04_2016.pdf.

Conforme explicitado na Tabela 2, dentre os 35 artigos analisados, 16 destacaram o City Manager como essencial para o combate a corrupção e/ou na eficiência da gestão municipal, 
outros 18 artigos não comentam sobre esse tema, e apenas um deles argumenta sobre a inexistência de diferença relevante entre o prefeito e o City Manager quanto aos quesitos: corrupção e eficiência. Interessante ressaltar que não foram encontrados artigos que afirmem que o cargo de City Manager é mais ineficiente ou que eleve os índices de corrupção da cidade em comparação ao cargo de prefeito.

Tabela 2. Combate a corrupção e melhora a eficiência

\begin{tabular}{l|c}
\hline \multicolumn{1}{c}{ Assunto } & Quantidade de artigos \\
\hline $\begin{array}{l}\text { Artigos que comentam a favor da forma de governo } \\
\text { com City Manager (eficiência e/ou combate a } \\
\text { corrupção) }\end{array}$ & 16 \\
\hline $\begin{array}{l}\text { Artigos que não abordam esse tema } \\
\text { Indiferente se é Prefeito ou City Manager }\end{array}$ & 18 \\
\hline $\begin{array}{l}\text { Artigos que comentam que outra forma de governo } \\
\text { é mais eficiente e/ou combate a corrupção melhor } \\
\text { que prefeituras que adotam o cargo de City } \\
\text { Manager }\end{array}$ & 0 \\
\hline Total & 35 \\
\hline
\end{tabular}

Fonte: Dados da pesquisa (2016)

Segundo Nelson e Svara (2012), a forma de governo prefeito-conselho, na qual o prefeito não elege um chefe administrativo com poderes e responsabilidades para conduzir a prefeitura é a forma de governo, das sete estudadas, com uma menor taxa de inovação. Verificase que muitos artigos científicos defendem uma forma de governo mais profissional, na qual o responsável administrativo das prefeituras seja escolhido pelo mérito e não por voto direto.

A forma de governo: conselho-gerente (City Manager) ou prefeito-conselho são as formas mais comum de governo nos Estados Unidos (Nelson \& Svara, 2012). A escolha do profissional City Manager pode ser feita das seguintes formas: escolhida pelo conselho, escolhida pelo prefeito, escolhida pelo prefeito e aprovada pelo conselho.

Com base nos resultados colhidos por esta pesquisa, verificou-se que há possibilidade de implementação do City Manager nas prefeituras brasileiras. A proposta de lei abaixo se baseou nos artigos científicos e nas legislações internacionais trazidas neste estudo. Algumas alterações foram adaptadas para as características da legislação brasileira e dos municípios brasileiros.

\section{Projeto de Lei federal proposto por este estudo que regulamenta a implementação, os poderes e os deveres do City Manager (Administrador Municipal).}

Art. $1^{\circ}$ Esta Lei tem como finalidade discriminar as normas gerais da implementação, dos poderes e dos deveres do Administrador Municipal

Art. $2^{\circ}$ A câmara dos vereadores após eleita deverá imediatamente contratar por tempo indeterminado um Administrador Municipal;

Art. $3^{\circ} \mathrm{O}$ Administrador Municipal deve ser eleito exclusivamente por mérito. Ao eleger o Administrador Municipal, a Câmara de Vereadores deve prestar devida atenção à formação, experiência, capacidade executiva e administrativa, eficiência, qualificações gerais e aptidão para desempenhar as funções do cargo. A Câmara não concederá nenhum peso ou consideração à filiação nacional, política ou religiosa, ou a quaisquer outras considerações, exceto mérito e qualificações diretas para o cargo;

Art. $4^{\circ}$ Os pedidos, registos, recomendações e qualificações de todos os candidatos ao cargo de 
Administrador Municipal devem ser abertos ao exame e à inspeção de todos os cidadãos; Art. $5^{\circ} \mathrm{O}$ salário do Administrador Municipal será fixado pela Câmara de Vereadores;

Art. $6^{\circ}$ A Câmara de Vereadores tem o poder de remover o Administrador Municipal a qualquer momento em que sua conduta se torne insatisfatória e eleger um sucessor no período máximo de seis meses da mesma forma anterior;

Art. $7^{\circ}$ A destituição do Administrador Municipal deve ser fundamentada por escrito e votada em Assembleia, respeitando o direito de defesa do Administrador Municipal;

Art. $8^{\circ} \mathrm{O}$ Administrador Municipal será o responsável pelos assuntos administrativos da cidade; Art. $9^{\circ} \mathrm{O}$ Administrador Municipal é responsável por verificar que todas as legislações sejam fielmente executadas no âmbito municipal;

Art. $10^{\circ} \mathrm{O}$ Administrador Municipal deve assistir as reuniões da Câmara de Vereadores e recomendar quaisquer medidas que ele considere oportunas;

Art. $11^{\circ}$ Apresentar relatórios financeiros e contábeis em conformidade com a Legislação federal, estadual e municipal para a Câmara de Vereadores e seus cidadãos;

Art. $12^{\circ}$ Preparar e apresentar o orçamento anual para a Câmara de Vereadores;

Art. $13^{\circ}$ Caberá aos Municípios criar normas específicas em conformidade com esta Lei Federal.

Esta proposta de lei tem o objetivo de propor uma nova forma de governo para os municípios brasileiros. O Administrador Municipal é escolhido pelo mérito e será a figura mais importante da cidade, sem prejudicar a democracia, pois o povo ainda elege o Administrador Municipal, indiretamente através dos vereadores eleitos.

Importante ressaltar que o Administrador Municipal fará atividades administrativas a qual atualmente são de responsabilidades do prefeito. Esta proposta de Lei também autoriza aos municípios brasileiros legislarem sobre este assunto de maneira específica, algo muito comum na legislação brasileira. Com isso, além de contribuir para uma gestão profissional, espera-se que os City Managers possam construir e facilitar o processo democrático entre a comunidade e o governo de uma forma mais transparente.

\section{CONCLUSÕES}

Desenvolveu-se este estudo com o intuito de propor uma lei federal que cria e regulamenta as diretrizes da implementação, dos poderes e dos deveres do cargo de City Manager nas prefeituras do Brasil. Para isso foram analisadas quatro legislações internacionais, manuais, organogramas de cidades e 35 artigos de periódicos internacionais.

Este estudo propõem a implementação da figura do City Manager nos munícipios brasileiros. Com está proposição a administração apresentara campos de atividades distintos, sendo tais: político e gestacional. Desse modo, afasta-se da gestão municipal a figura exclusivamente política e valores políticos de cada partido. Na referida proposição, os City Managers ficam responsáveis pelo fornecimento de seus conhecimentos técnicos na qualidade de uma assessoria neutra, tendo por finalidade a de auxiliar os vereadores a criarem e votarem as propostas de políticas municipais interessantes ao bem comum.

A proposta de legislação se baseou na forma de governo conselho-gerente, sendo está muito utilizada nos Estados Unidos. A figura do conselho seria representada pela Câmara de Vereadores, a qual é composta por representantes eleitos diretamente pela população municipal. Aos vereadores da cidade incube o papel de eleger os City Managers a qual deve ser feita baseada, exclusivamente, em mérito. O City Manager, quando possuidor de boa capacidade administrativa e de gestão é capaz de gerir com uma maior eficiência a prefeitura municipal, estando afastados interesses políticos partidários, visto não possuir filiação. Do mesmo modo, 
será inibida a defesa de interesses distintos da busca por uma boa gestão e o bem comum, fato que irá colaborar para o cumprimento dos princípios que regem a Administração Pública no Brasil, dentre eles o da impessoalidade.

O presente artigo limitou-se a analisar periódicos já publicados, legislações internacionais, organogramas e manuais sobre o tema. Como sugestão para trabalhos futuros, seriam válidas construções de novas legislações, trazendo também resultados de entrevistas com políticos, servidores e estudiosos da Administração pública afim de melhor adaptar o cargo de City Manager nas prefeituras brasileiras.

\section{REFERÊNCIAS}

Ammons, D. N. (2008) City manager and city administrator role similarities and differences: Perceptions among persons who have served as both. The American Review of Public Administration, v. 38, n. 1, p. 24-40.

Avellaneda, C. N. (2009) Municipal Performance: Does Mayoral Quality Matter? Journal of Public Administration Research and Theory, v. 19, n. 2, p. 285-312.

Charles, A. R. (1999) "Forms of Local Government in American History." In Forms of Local Government. A Handbook on City, County and Regional Options, edited by Roger L. Kemp. Jefferson: McFarland \& Company.

Chicksand, D., Watson,G. \& Walker, H. (2012)Theoretical perspectives in purchasing and supply chain management: ananalys is of the literature. Supply Chain Management $17,454-472$.

Cooper, D. R. \& Schindler, P. S. (2003) Métodos de Pesquisa em Administração. 7. ed. Porto Alegre: Bookman.

Couperus, S. (2014) The managerial revolution in local government: municipal management and the city manager in the USA and the Netherlands 1900-1940. Management and Organizational History, v. 9, n. 4, p. 336-352.

Demir, T. (2011) Professionalism, responsiveness, and representation: What do they mean for city managers? International Journal of Public Administration, v. 34, n. 3, p. 151-158.

Demir, T \& Reddick, C. G. (2015) Political Orientation and Policy Involvement of City Managers: An Empirical Study of the Value-Activity Relationship. Public Organization Review, v. 15, n. 4, p. 581-598.

Fahimnia, B. et al, (2015) "Green supply chain management: A review and bibliometric analysis," International Journal of Production Economics, Elsevier, vol. 162(C), p. 101114.

Fonseca, J. J. S. (2002) Metodologia da pesquisa científica. Fortaleza: UEC, Apostila.

Hirschhorn, B. (1997) Democracy Reformed: Richard Spencer Childs and His Fight for Better Government. Westport: Greenwood Press.

Leite, L \& Rezende, D. (2010) Modelo de gestão municipal baseado na utilização estratégica de recursos da tecnologia da informação para a gestão governamental: formatação do modelo e avaliação em um município. Revista de Administração Pública RAP. 
Mikheeva, T. N. \& Kudryavtsev, V. V. (2015) Transparency in the process of formation of the local administration: A comparative legal analysis. Asian Social Science, v. 11, n. 19, p. 98-105.

Mischiatti, J. A.W., Moleta, E. J. \& Catapan, A. (2016) City Manager: Uma Análise Bibliométrica de 1950--2016. III Seminário Nacional de Planejamento e Desenvolvimento, 2016, Campos dos Goytacazes. Anais do III Seminário Nacional de Planejamento e Desenvolvimento.

Revised Statutes of Missouri, USA, Chapter 78. Dispõe sobre regulamentação do City Manager no estado de Missouri, EUA. Disponível em:

$<$ http://www.moga.mo.gov/mostatutes/chapters/chapText078.html $>$. Acesso em $10 \mathrm{de}$ nov. 2016.

Morgan, D. R.; Watson, S. S. (1992) Policy Leadership in Council-Manager Cities: Comparing Mayor and Manager. Public Administration Review, v. 52, p. 438-447.

Nalbandian, J. (1999) Facilitating Community, Enabling Democracy: New Roles for Local. Government Managers. Public Administration Review, v. 59, p. 187-197.

Nelson, K. L.; Svara, J. H. (2012) Form of Government Still Matters: Fostering Innovation in U.S. Municipal Governments. American Review of Public Administration, v. 42, n. 3, p. 257-281.

Noordegraaf, M. (2007) From "pure" to "hybrid" professionalism: Present day professionalism in ambiguous public domains. Administration \& Society, 39(6), 761785 .

General Statutes of North Carolina, USA Chapter 160 A. Dispõe sobre regulamentação do City Manager no estado de Carolina do Norte, EUA. Disponível em: http://www.ncleg.net/EnactedLegislation/Statutes/HTML/ByChapter/Chapter_160A.ht $\mathrm{ml}>$ Acesso em 10 de nov. 2016.

Pfeiffer, P. (2000) Planejamento estratégico municipal no Brasil: uma nova abordagem. Brasília: Enap.

Reddick, C. G.; Demir, T. (2014) Professional Identification and City Managers: An Analysis of a National Survey. International Journal of Public Administration, v. 37, n.3, p.174182.

Rezende, D. A. (2005) Planejamento de informações públicas municipais: guia para planejar sistemas de informação, informática e governo eletrônico nas prefeituras e cidades. São Paulo: Atlas.

Rightor, C E. (1919) City Manager in Dayton. New York: Macmillan.

Stenberg, C. W. (2014) County and City Managers. UNC Chapel Hill School of Government, Chapter 4. Disponível em:

$<$ https://www.sog.unc.edu/sites/www.sog.unc.edu/files/course_materials/CMG\%2004_ Managers.pdf $>$. Acesso em: 10 de nov. 2016.

Vilaça, M. L. C. (2010) Pesquisa e Ensino. Considerações e Reflexões. Revista E-scrita Volume 1. Número 2. 
White, L. D. 1927. The City Manager. Chicago: University of Chicago Press.

State Legislature of Wisconsin, USA Chapter 64. Dispõe sobre regulamentação do City Manager no estado de Wiscosin, EUA. Disponível em:

$<$ http://docs.legis.wisconsin.gov/statutes/statutes/64>. Acesso em: 10 de nov. de 2016. 